\title{
Seismic performance assessment of conventional steel and steel-concrete composite moment frames using CFST columns
}

\author{
A. Silva ${ }^{a, b}$, Y. Jiang ${ }^{a, b}$, L. Macedo ${ }^{b}$, J.M. Castro ${ }^{b^{*}}$ and R. Monteiro $^{a}$ \\ ${ }^{a}$ Universitario di Studi Superiori di Pavia, Italy \\ ${ }^{\mathrm{b}}$ Faculty of Engineering, University of Porto, Portugal \\ *corresponding author, e-mail address: miguel.castro@fe.up.pt
}

\begin{abstract}
The research reported in this paper focuses on the assessment of the seismic performance of conventional steel moment-resisting frames (MRFs) and steel-concrete composite moment-resisting frames employing circular Concrete-Filled Steel Tube (CFST) columns. Two comparable archetypes (i.e. one steel MRF, with steel columns and steel beams; and one composite MRF, with circular CFST columns and steel beams) are designed, and used as the basis for comparison between the seismic performance associated with each typology. Both structures are designed against earthquake loads following the recommendations of Eurocode 8. The comparison of the obtained design solutions allows concluding that the amount of steel associated with the main structural members is higher for the steel-only archetype, even though the composite MRF has the higher level of lateral stiffness. This aspect is particularly relevant when one considers that a minimum level of lateral stiffness (associated with the P- $\Delta$ inter-storey drift sensitivity coefficient, $\theta$ ), is imposed by the European code, which may ultimately govern the design process. The two case-studies are then numerically modelled in OpenSees, and their seismic performance is assessed through fragility assessment for a number of relevant limit states, and, finally, earthquake-induced loss estimation. In general, the results obtained clearly indicate that the composite MRF with circular CFST columns exhibits better seismic performance than the equivalent steel-only archetype. This is noticeably shown in the comparison of the fragility curves associated with the collapse limit state, which tend to show substantially higher probabilities of exceedance, at similar levels of $1^{\text {st }}$-mode spectral acceleration, for the steelonly case. Furthermore, seismic losses at several seismic intensity levels of interest tend to be higher for the steel MRF.
\end{abstract}

Keywords: steel/composite moment frames, concrete-filled steel tubes; Eurocode 8; seismic performance; earthquake-induced losses.

\section{Introduction}

Concrete-filled steel tubular (CFST) members have gained relevance in recent decades as an alternative solution for seismicresistant applications, in light of several advantages over conventional technologies (e.g. reinforced concrete, steel). Due to the synergy that stems from the efficient combination of concrete at the core of the member, and steel tubular sections as the encasing part, both the members' strength and ductility are improved significantly over the isolated behaviours of the parts, and energy dissipation characteristics of these composite members also tend to be attractive. In particular, the interaction between the core and the encasing tube may entail the development of multi-axial stress effects (e.g. concrete confinement), whilst hindering the development of local buckling phenomena of the steel part (i.e. inwards local buckling is prevented, outwards local buckling is delayed to larger levels of deformation). In line with these characteristics, the experimental study of the flexural behaviour of beam-column CFSTs has also gained some visibility in the last few decades (e.g. Elchalakani et al. [1], Varma et al. [2][3], Han et al. [4], Silva et al. [5][6]), with good ductility and overall behaviour being exhibited by the composite members. 
Notwithstanding, the effect of employing CFST members on the seismic performance of moment framed systems still remains an open topic in the literature. Hence, this study specifically aims to provide a meaningful contribution, by, through fragility assessment and earthquake-induced loss estimation, gauging the effect of employing circular CFST columns in detriment of steel open-profile sections, in the context of momentresisting framed buildings.

\section{Archetype frames}

\subsection{General description}

For this study, a 5-storey MRF building structure was considered, with the layout in plan and elevation shown in Fig. 1. In the longitudinal (X) direction the seismic resistance is provided by moment-resisting frames spaced at 6 meters. In the transverse $(\mathrm{Y})$ direction the seismic resistance is assured by a bracing system. The investigation detailed in this paper focuses on the internal MRF.

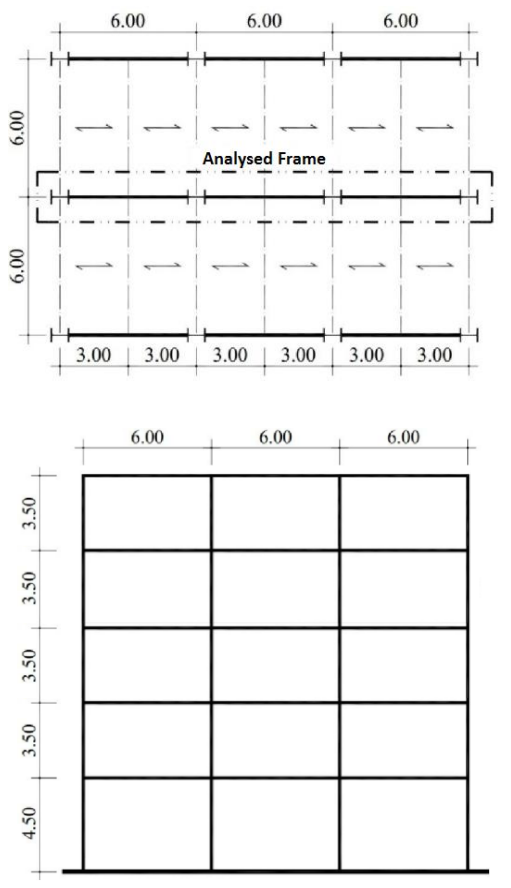

Fig. 1. Building layout

All frames were designed in accordance with Eurocode 8 [7], with the added recommendations set in the Portuguese National Annex. The frames were designed under the DCM (medium ductility) class of the code, with a behaviour factor of 4 . The steel grade considered for all steel elements was S275, and a concrete class $\mathrm{C} 30 / 37$ was assumed for the concrete core of the CFST columns. European steel open sections with I shape (IPE) and H shape (HEB) were used for the steel beams and columns, respectively, and commercial steel tubular sections were adopted for the CFST members. A summary of the gravity loads considered is shown in Table 1 , where $g_{k}$ and $q k$ are the permanent and imposed loads, respectively. The transmission of the vertical loads to the central frame was considered through point loads applied at each storey level, in accordance with the layout of the secondary beams. The slabs were considered to act as rigid diaphragms, thus, each storey mass can be equally distributed by the three longitudinal frames, as shown in Table 1. The parameters required for the definition of the elastic response spectra for soil type B that are specified in the Portuguese National Annex of Eurocode 8 are shown in Table 2.

Table 1. Gravity loads and frame storey seismic masses.

\begin{tabular}{cccc}
\hline Storey & Load type & $\begin{array}{c}\mathbf{p} \\
{\left[\mathbf{k N} / \mathbf{m}^{\mathbf{2}}\right]}\end{array}$ & $\begin{array}{c}\mathbf{M} \\
{[\mathbf{t}]}\end{array}$ \\
\hline Top storey & $\mathrm{g}_{\mathrm{k}}$ & 4.75 & 34.2 \\
Intermediat & $\mathrm{q}_{\mathrm{k}}$ & 1.00 & \\
e storey & $\mathrm{g}_{\mathrm{k}}$ & 5.75 & 45.7 \\
\hline
\end{tabular}

Table 2. Elastic response spectra parameters.

\begin{tabular}{ccccccc}
\hline \multirow{2}{*}{ Type } & \multirow{2}{*}{ Region } & $\begin{array}{c}\mathbf{a g}_{\mathbf{g}} \\
{[\mathbf{g}]}\end{array}$ & $\mathbf{S}$ & $\begin{array}{c}\mathbf{T}_{\mathbf{B}} \\
{[\mathbf{s}]}\end{array}$ & $\begin{array}{c}\mathbf{T}_{\mathbf{C}} \\
{[\mathbf{s}]}\end{array}$ & $\begin{array}{c}\mathbf{T}_{\mathbf{D}} \\
{[\mathbf{s}]}\end{array}$ \\
\hline 1 & \multirow{2}{*}{ Lagos } & 0.25 & 1.175 & 0.10 & 0.60 & 2.00 \\
2 & & 0.17 & 1.268 & 0.10 & 0.25 & 2.00 \\
\hline
\end{tabular}

Seismic design was conducted taking into account second-order effects, by limiting the maximum value of the inter-storey drift sensitivity coefficient, $\theta$, to 0.2 . The EC 8 capacity design weak beam-strong column requirement was also considered in the design of the frames. The damage limitation performance requirement was considered by limiting the inter-storey drift to $0.75 \%$ of the storey height. All archetypes were designed based on the modal response spectrum analysis method. Two different alternatives were used for the design of the MRF, namely a steel-only solution (steel beams and columns) and a composite solution (steel beams and CFST columns). Both cases were considered equivalent, in the sense that the building and frame layout, gravity loads, seismic location, ductility class, design criteria (e.g. P- $\Delta$ 
effects, capacity design, and damage limitation) and design method are shared.

\subsection{Comparison of design solutions}

The design solutions are provided in Table 3 and Table 4, and a summary is shown in Table 5. In Table 5, the designation of the member section is specified in terms of the relationship between the external diameter, $d$, and thickness, $t$, of the steel tube, as $d x t$.

Table 3. Design solution of the steel archetype.

\begin{tabular}{cccc}
\hline Storey & Beams & $\begin{array}{c}\text { Exterior } \\
\text { Columns }\end{array}$ & $\begin{array}{c}\text { Interior } \\
\text { columns }\end{array}$ \\
\hline 5 & IPE300 & HEB300 & HEB320 \\
4 & IPE300 & HEB320 & HEB340 \\
3 & IPE330 & HEB320 & HEB340 \\
2 & IPE360 & HEB320 & HEB360 \\
1 & IPE400 & HEB320 & HEB360 \\
\hline
\end{tabular}

Table 4. Design solution of the composite archetype.

\begin{tabular}{cccc}
\hline Storey & Beams & $\begin{array}{c}\text { Exterior } \\
\text { Columns }\end{array}$ & $\begin{array}{c}\text { Interior } \\
\text { columns }\end{array}$ \\
\hline 5 & IPE300 & $323.9 \times 6$ & $404.6 \times 6$ \\
4 & IPE330 & $323.9 \times 6$ & $404.6 \times 10$ \\
3 & IPE330 & $323.9 \times 8$ & $404.6 \times 10$ \\
2 & IPE400 & $323.9 \times 8$ & $404.6 \times 10$ \\
1 & IPE400 & $323.9 \times 10$ & $404.6 \times 12$ \\
\hline
\end{tabular}

Table 5. Design summary of the steel and composite archetypes.

\begin{tabular}{cccccc}
\hline Case & $\begin{array}{c}\mathbf{T}_{\mathbf{1}} \\
{[\mathbf{s}]}\end{array}$ & $\boldsymbol{\Omega}$ & $\boldsymbol{\theta}_{\mathbf{M A X}}$ & $\begin{array}{c}\mathbf{W}_{\mathbf{S}} \\
{[\mathbf{t}]}\end{array}$ & $\begin{array}{c}\mathbf{W}_{\mathbf{C}} \\
{\left[\mathbf{m}^{\mathbf{3}}\right]}\end{array}$ \\
\hline Steel & 1.18 & 3.05 & 0.19 & 14.3 & - \\
CFST & 1.14 & 2.41 & 0.17 & 10.4 & 13.0 \\
\hline
\end{tabular}

As denoted by the results shown in Table 5, the use of CFST columns allows, in detriment of conventional steel sections, for the same design conditions, for a reduction in steel quantity of the main structural members in the order of $30 \%$. This is mainly due to the fact that the governing design criteria was compliance with the limitation of $\theta$ to 0.2. Since this parameter effectively imposes a minimum level of lateral stiffness on the structure, one can straight way see that using a composite member should be much more efficient that a conventional steel section: for the same quantity of steel, the CFST member can provide significantly higher levels of lateral stiffness. Hence, one ends up with a lighter (purely in terms of steel quantity) solution with the use of CFST columns, even though the maximum value of $\theta$ in both cases is fairly similar. It is also important to note that the system overstrength levels of the composite scenario are around 20\% lower than the steelonly solution. One should recall that this parameter provides a rough notion of the amount of strength reserve the structure possesses against the design level earthquake. In reality, the ratio of $\Omega / q$ (under an idealized elastic perfectly-plastic response) provides an idea of the level of nonlinear response expected in the structure when subjected to the design earthquake: $\Omega / q<1.0$ entails that the structure is likely to enter the nonlinear range, whilst for $\Omega / q>1.0$ the structure should behave elastically when subjected to the design earthquake. Thus, one can easily conclude that the composite system should allow for a seismic response that explores more nonlinear behaviour of the structure. To conclude, one should also note that although the steel quantity was reduced in the composite case, this was attained by the introduction of some concrete in the solution. Notwithstanding, the considerable difference in material cost between concrete and steel results in an almost insignificant contribution of the infill of the CFST members to the overall structural cost. However, one should also note that the overall cost of the structure may actually increase with the use of CFST columns, given that member joints, foundations and construction time, are aspects that could become more complex and costly. Nonetheless, even if the overall cost of the composite frame is equivalent or higher than that of a steel frame, this may be justifiable if benefits are achieved from a seismic performance perspective.

\section{Seismic performance assessment}

\subsection{Simplified numerical modelling}

The seismic performance of the steel-only and steel-concrete frames described before was performed in OpenSees [8], by adopting a simplified numerical modelling approach. Both beam and column members were simulated with nonlinear behaviour allowed to take place at the members' ends, as per a concentrated plasticity (CP) approach. The CP model consists of one elastic beam-column element and two nonlinear rotational springs, which are lumped at the member ends. The cyclic response of the $\mathrm{CP}$ model is mainly governed by the hysteretic rule of the nonlinear spring. Thus, to make the CP model simulate the flexural behaviour of CFST members in an accurate manner, a suitable 
model for the nonlinear spring should be selected. Using CalTool [10], the numerical parameters of the rotational hinge model in OpenSees underwent an optimized calibration procedure. This process makes use of advanced full 3D numerical models of cantilever elements subjected to both monotonic and cyclic bending, from which the deterioration model parameters of the CP elements in OpenSees are calibrated. Whilst a bilinear hysteretic response was adopted for steel beams and columns, a peakoriented hysteretic response was considered for the simulation of the behaviour of CFST columns. The modified Ibarra-KrawinklerMedina deterioration model with peak-oriented hysteretic response [9] was adopted as the nonlinear spring model for all members. Whilst bilinear hysteretic response was adopted for steel beams and columns, peak-oriented hysteretic response was utilized to simulate the behaviour of CFST columns. The advanced numerical modelling of the steel beams and columns was performed in ANSYS [11] and of the CFST elements in ABAQUS [12]. Fig. 7 and Fig.8 show two examples of the aforementioned calibration procedure, namely in terms of a comparison of the behaviour of both the detailed 3D model (ANSYS and ABAQUS, respectively) and the concentrated plasticity simplified model in OpenSees. Overall, a good correlation between both models was achieved with the use of a calibration procedure to determine the deterioration model parameters, allowing for a realistic simulation of the response of the moment-resisting frames in OpenSees.

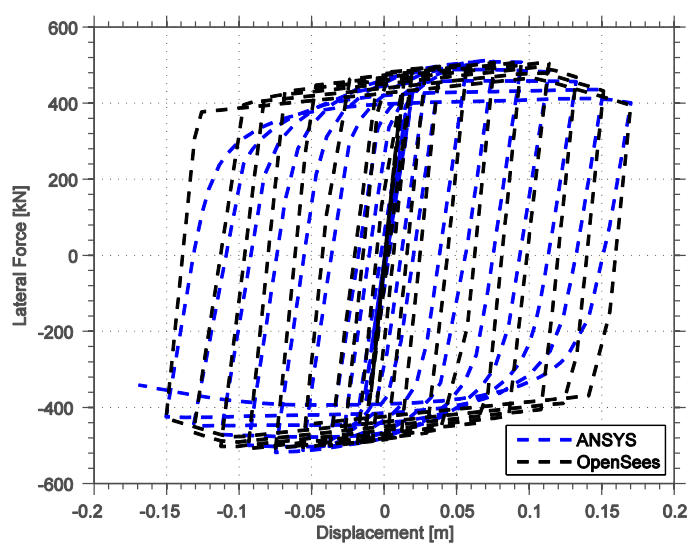

Fig. 2. Calibration of the concentrated plasticity model for a steel HEB340 member.

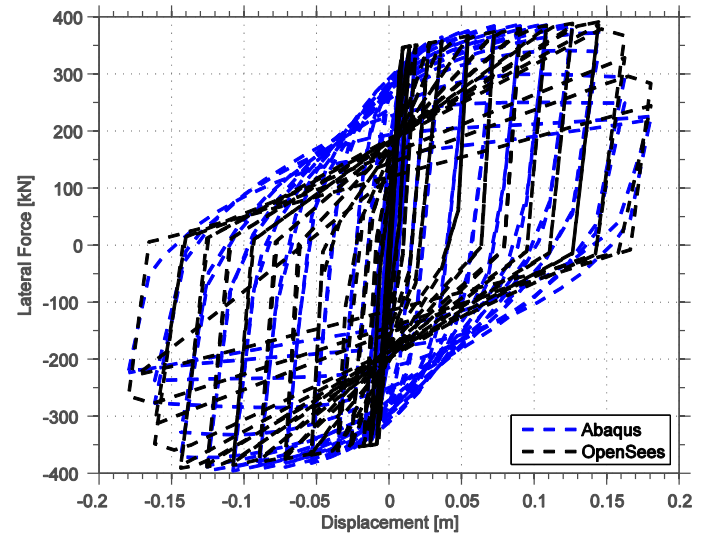

Fig. 3. Calibration of the concentrated plasticity model for a circular CFST 404.6x12 member.

\subsection{Site hazard and ground motion record selection}

A single location in Portugal (i.e. Lagos), was considered in this study, both for design and seismic performance assessment purposes. Probabilistic Seismic Hazard Analysis (PSHA) was performed for the site in question, using the open source software OpenQuake (Pagani et al. [13] and the seismic hazard model developed in SHARE (Woessner et al. [14]), whilst also including additional hazard sources (Vilanova and Fonseca [15]) and employing the ground motion prediction equations from Atkinson and Boore [16] and Akkar and Bommer [17], with a weight of $70 \%$ and $30 \%$, respectively (Silva et al. [18]). Disaggregation of the seismic hazard (Bazurro and Cornell [19]) on magnitude, distance and $\varepsilon$ was performed. Record selection was conducted based on the disaggregation results and an average shear wave velocity for the first 30 meters of soil, $\mathrm{V}_{\mathrm{s} 30}$, was considered. For this location, a suite of 40 ground motion records was selected and scaled to match the median spectrum of the suite to the codes' spectrum within a range of periods of interest. A similar technique was applied in the FEMA P695 project (FEMA [20]). As proposed by Haselton et al. [21], a general ground motion record suite was selected without taking into account the $\varepsilon$ values, with the results being post-processed to account for the expected $\varepsilon$ at a specific site and hazard level. Records were selected using SelEQ (Macedo and Castro [22]), which allowed for a very good correlation between the mean/median spectrum of the selected ground motions and the code spectrum. Fig. 4 shows the mean and median response spectra of the ground motion 
suite Lagos, together with the corresponding EC8 response spectrum for a hazard level of $10 \%$ in 50 years.

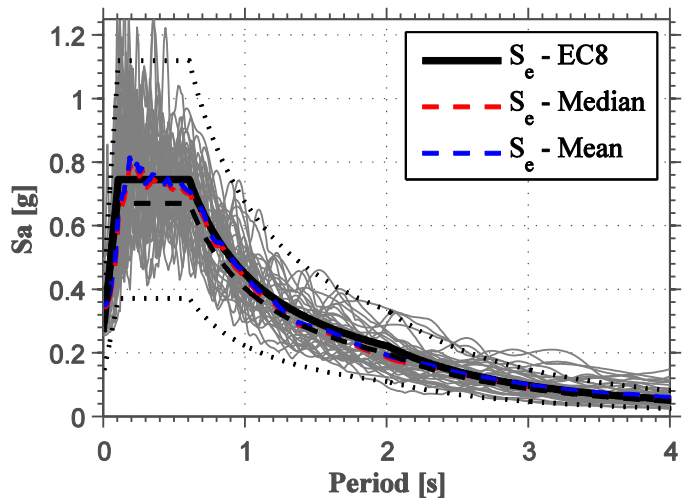

Fig. 4. Mean and median response spectra of ground motion record set and EC8 elastic spectrum for Lagos.

\subsection{Simplified loss estimation approach}

Among the possible methodologies for loss estimation, the PEER-PBEE approach (Porter [23]) has become the reference procedure to estimate damage and economic losses resulting from an earthquake. In this research study, the $1^{\text {st }}$ mode spectral acceleration, $S_{a}\left(T_{1}\right)$, was used as the relevant intensity measure, IM, whilst the engineering demand parameters, EDPs, considered were the maximum and residual inter-storey drifts (RISDR), as well as the peak floor accelerations. The damage functions, DM, were derived from the HAZUS (Kircher et al. [24]) consequence and fragility models. Collapse probability was determined based on IDA (Vamvatsikos and Cornell [25]), assumed to occur if the slope of the IDA curve reduces to $10 \%$ of the initial value, or if the inter-storey drift ratio of any storey exceeds $20 \%$. A simplified storey-based building-specific loss estimation method (Ramirez and Miranda [26]) was adopted to estimate the total losses based on the sum of the repair costs at each storey of the building. Moreover, at each storey the components were grouped into drift-sensitive structural and non-structural components, as well as acceleration-sensitive non-structural components. At each storey, these categories were weighted at $25 \%, 55 \%$ and $20 \%$, respectively, a proportion that is in line with the construction practice in Portugal. By adopting the procedure proposed by Ramirez and Miranda [27], the storey fragility and consequence models have been derived from HAZUS generic data which, considering residential multi-family dwellings, designed for a "highcode" level. Combining the consequence models with the corresponding fragility functions, the storey damage functions could be obtained, and storey damage functions re-scaled with the component category weights assumed. In this research study, a single loss metric was considered, namely the expected losses conditioned on seismic intensity levels of interest, namely: SLS1 (EC8-1 [7] Serviceability Limit State, Return period, RP, of 95 years), SLS-3 (EC8-3 [28] Damage Limitation limit state, RP of 225 years), SD (EC8-3 Significant Damage limit state, RP of 475 years) and NC (EC8-3 Near Collapse limit state, RP of 2475 years).

\section{Comparison of seismic performances}

\subsection{Collapse fragility}

The first criterion that was used to assess the performance of the archetypes under seismic loads consists of the computation of fragility curves for the collapse limit state. As mentioned before, this limit state was defined via the flattening of the IDA curves. From this analysis, the collapse fragility curves, expressed as a function of $S_{a}\left(T_{1}\right)$, are shown in Fig. 5. Analysis of the results shown in both figures clearly shows a tendency for substantially higher probabilities of exceedance of this limit state, at similar levels $S_{a}\left(T_{1}\right)$, for the steel-only case. One particular point that is important to underline is that these frames were designed with capacity principles in mind, as per EC8, with the dissipative regions of the system being assigned to the beam ends and base of the $1^{\text {st }}$ storey columns. Given this fact, one could expect that using different column types (i.e. CFST or steel), with the same beam type (steel beam), would not affect the dissipative behaviour of the structure. Although this is true, capacity design was applied for the Ultimate Limit State intensity level $\left(S_{e}\left(T_{l}\right) \approx 0.4 \mathrm{~g}\right)$. However, for the structure to reach collapse, the intensity levels required are significantly higher than this, in which case plasticity should likely spread to other columns of the frame. Hence, if sections with more stable nonlinear response are assigned to the columns, this should also entail a more stable respons of the frame itself under extreme scenarios (e.g. collapse). 

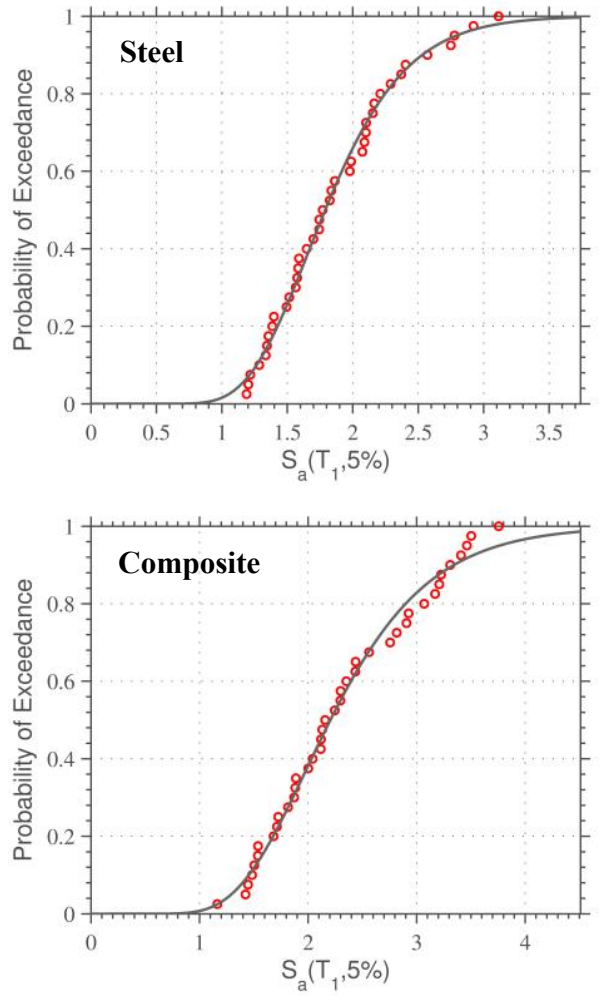

Fig. 5. Collapse fragility curves.

\subsection{Earthquake-induced losses}

The second criterion that was used to gauge the effect of using CFST columns against steel open-sections relates to the expected seismic losses, which, in this paper, were computed for a wide range of intensity levels, and are herein summarized in terms of the intensity levels considered in the framework of Eurocode 8. As mentioned before, the application of the loss estimation framework adopted allows for the disaggregation of the losses between the key contributors: losses due to structural and nonstructural damage, losses due to demolition due to excessive residual drift, and losses due to collapse of the building, as shown in Fig. 6. As shown in both cases, total losses range from $20 \%-50 \%$ of the buildings' replacement cost for the steel case, and are generally 5\% lower than that for the composite case (with the exception of the CLS intensity level, in which the total losses are identical). Also, in both cases, the amount of losses due to collapse are null, indicating that the design against collapse seems to be successful, even at a CLS-compatible intensity level, which is roughly $80 \%$ higher that the intensity level at ULS, to which the structures were designed for. Demolition losses in the composite case at CLS were higher, indicating that residual deformations experienced by the structure are higher and/or more concentrated than for the steel archetype. This can be confirmed in Fig. 7, in which the distributions of several EDPs are shown for the intensities of interest used for loss computation. In the plots, the $2^{\text {nd }}, 3^{\text {rd }}$ and $4^{\text {th }}$ curves in each subplot correspond to the SLS-1, SD and CLS intensity level, respectively (the remaining curves corresponded to an elastic response $-1^{\text {st }}-$ and maximum intensity level ran $-5^{\text {th }}$ ). It is important to highlight that even though the levels of losses were generally lower for the composite case, the values of $S_{a}\left(T_{l}\right)$ at the different intensities of interest were actually $10 \%$ higher than for the steel case, which is, again, in line with the general message presented herein: CFST columns are a good alternative to steelonly open-section columns for seismic performance.
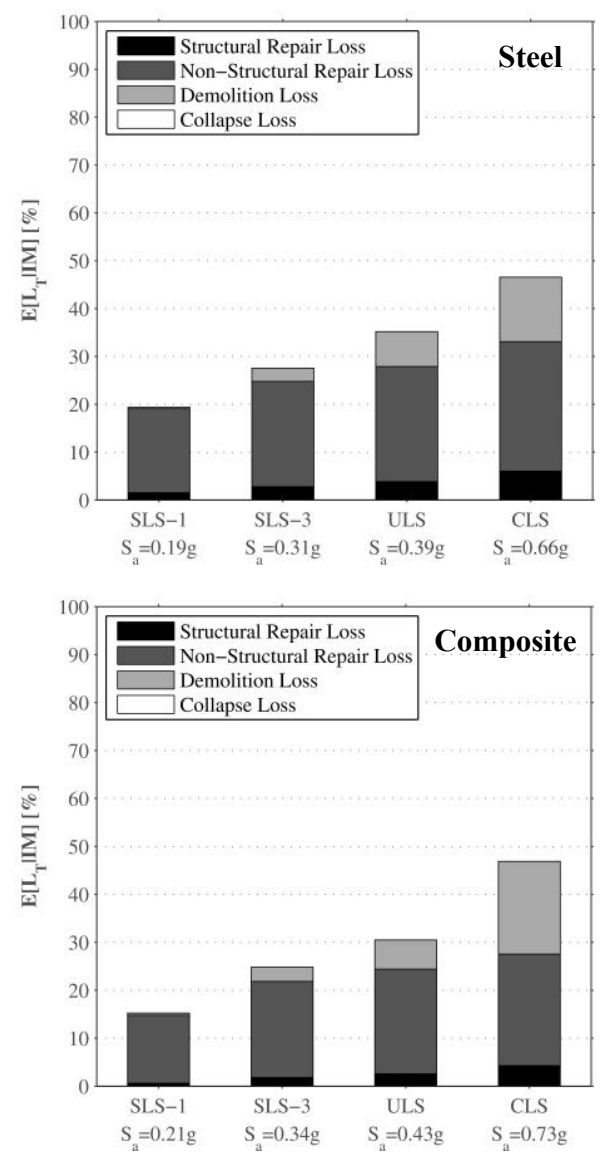

Fig. 6. Seismic losses at different intensities of interest. 


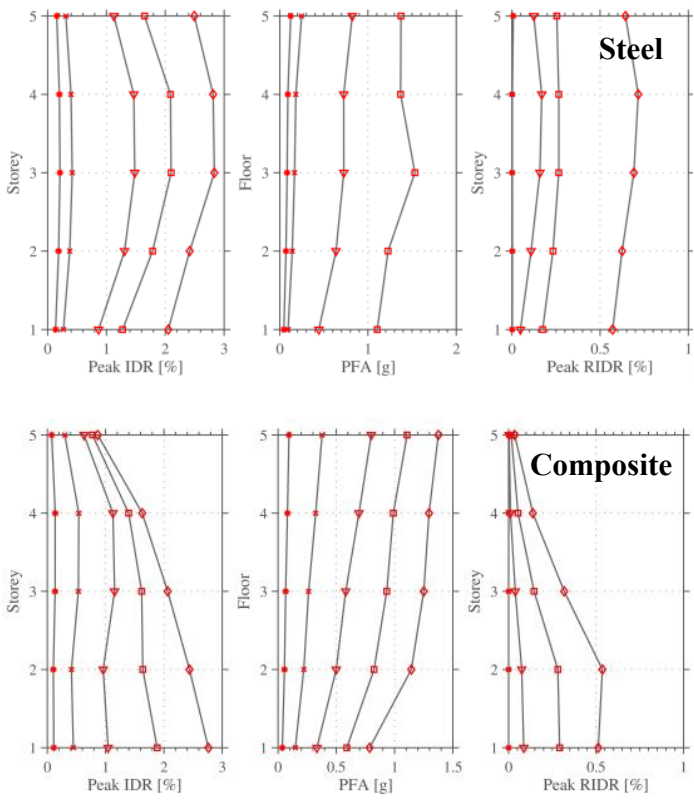

Fig. 7. EDP distributions at intensities of interest.

Before concluding, the results shown before also merit another observation: for both cases, seismic losses are largely dominated by damage to non-structural components (both drift- and acceleration-sensitive), ranging between $20 \%$ $30 \%$ of the buildings replacement cost for the steel case and $15 \%-25 \%$ for the composite case, across the intensity levels considered. This is a crucial aspect to underline: current performancebased seismic design guidelines should undergo a shift towards stronger earthquake-induced loss control approaches, particularly regarding damage to non-structural components. The main objective of the past decades of seismic design methodologies (i.e. collapse prevention) is, nowadays, generally successful. However, significant levels of damage to non-structural components may actually compromise this success: the building does not suffer collapse, but the damages to the contents are somewhat uncontrolled at the design stage. In Eurocode 8, for example, some limits on lateral deformations at the SLS are imposed, but any control of floor accelerations is completely overlooked.

\section{Conclusions}

In this paper, the effects of using CFST columns in moment frames was assessed, through a comparison of the seismic performance in relation to a steel-only MRF. Two 5-storey equivalent archetypes were designed to EC8, in which some benefits of the composite approach were already visible: $30 \%$ less steel quantity overall and reduced overstrength $(\Omega)$ levels. By investigating the performance of both cases through collapse fragility assessment, the results indicated higher probabilities of exceedance of this limit state, at similar levels $S_{a}\left(T_{1}\right)$, for the steel-only case. Earthquake-induced loss levels were also estimated, from which the conclusion that generally lower levels of losses are expected to occur for the composite case. The underlining notion that the use of CFST columns, in detriment of steel open-section profiles, for moment frames was shown: savings in material quantity may be relevant (even if undermined by more complex member connections, foundations, construction processes), as so may be the improvements in expected seismic performance levels.

\section{References}

[1] Elchalakani M, Zhao XL, Grzebieta R. Concretefilled circular steel tubes subjected to pure bending. Journal of Constructional Steel Research 2001;57(11):1141-1168.

[2] Varma A, Ricles J, Sause R, Lu LW. Experimental behavior of high strength square Concrete-Filled Steel Tube beam-columns. Journal of Structural Engineering 2002;128(3):309-318.

[3] Varma A, Ricles J, Sause R, Lu LW. Seismic behavior and modeling of high-strength composite concrete-filled steel tube (CFT) beamcolumns. Journal of Constructional Steel Research 2002;58(5-8):725-758.

[4] Han LH, Lu H, Yao GH, Liao FY. Further study on the flexural behaviour of concrete-filled steel tubes. Journal of Constructional Steel Research 2006;62(6):554-565.

[5] Silva A, Jiang Y, Castro JM, Silvestre N, Monteiro R. Experimental assessment of the flexural behaviour of circular rubberized concrete-filled steel tubes. Journal of Constructional Steel Research 2016;122:557570.

[6] Silva A, Jiang Y, Castro JM, Silvestre N, Monteiro R. Monotonic and cyclic flexural behaviour of square/rectangular rubberized concrete-filled steel tubes Journal of Constructional Steel Research 2017;139:385396.

[7] CEN. EN 1998-1 Eurocode 8: Design of structures for earthquake resistance. Part 1, General rules, seismic actions and rules for buildings. European Commitee for Standardization, Brussels, Belgium, 2004. 
[8] Mazzoni S, McKenna F, Scott MH and Fenves GL. The Open System for Earthquake Engineering Simulation (OpenSEES) User Command-Language Manual, 2006.

[9] Lignos DG and Krawinkler H. Development and utilization of structural component databases for performance-based earthquake engineering. Journal of Structural Engineering 2012, 139(8): 1382-1394.

[10] Araújo M, Macedo L, Castro JM. Calibration of strength and stiffness deterioration hysteretic models using optimization algorithms. Proceedings of the $8^{\text {th }}$ International Conference on Behaviour of Steel Structures in Seismic Areas, 2015, Shanghai, China.

[11]ANSYS. ANSYS Structural Analysis Guide. ANSYS, Inc., Canonsburg, PA, USA, 2009.

[12] ABAQUS. ABAQUS Documentation. Dassault Systèmes Simulia Corp., Providence, RI, USA, 2011.

[13] Pagani M, Monelli D, Weatherill G, Danciu L, Crowley H, Silva V, Hanshaw P, Butler L, Nastasi M, Panzeri L, Simionato M, Viganò D. OpenQuake Engine: An Open Hazard (and Risk) Software for the Global Earthquake Model. Seismological Research Letters 2014;85(3):692702.

[14] Woessner J, Danciu L, Giardini D, Crowley H, Cotton F, Grünthal G, Valensise G, Arvidsson R, Basili R, Demircioglu MN, Hiemer S, Meletti C, Musson RW, Rovida AN, Sesetyan K, Stucchi M, the SHARE consortium. The 2013 European Seismic Hazard Model: key components and results. Bulletin of Earthquake Engineering 2015;13(12):3553-3596.

[15] Vilanova SP, Fonseca JFBD. Probabilistic Seismic-Hazard Assessment for Portugal. Bulletin of the Seismological Society of America 2007;97(5):1702-1717.

[16] Atkinson GM, Boore DM. Earthquake GroundMotion Prediction Equations for Eastern North America. Bulletin of the Seismological Society of America 2006;96(6):2181-2205.

[17] Akkar S, Bommer JJ. Empirical equations for the prediction of PGA, PGV and spectral accelerations in Europe, the Mediterranean region and the Middle East. Seismological Research Letters 2010;81(2):195-206.

[18] Silva V, Crowley H, Varum H. Seismic risk assessment for mainland Portugal. Bulletin of Earthquake Engineering 2015;13:429-457.

[19]Bazurro P, Cornell CA. Disaggregation of Seismic Hazard. Bulletin of the Seismological Society of America 1999;89(2):501-520.

[20]FEMA. FEMA P695: Quantification of building seismic performance factors. Federal Emergency
Management Agency (FEMA), Washington, D.C., USA, 2009.

[21] Haselton CB, Liel AB, Deierlein GG, Dean BS, Chou JH. Seismic Collapse Safety of Reinforced Concrete Buildings: I. Assessment of Ductile Moment Frames. Journal of Structural Engineering 2011;137(4):481-491.

[22] Macedo L, Castro JM. SelEQ: An advanced ground motion record selection and scaling framework. Advances in Engineering Software 2017; 14:32-47.

[23]Porter KA. An Overview of PEER's Performance-Based Earthquake Engineering Methodology. Proceedings of 9th International Conference on Applications of Statistics and Probability in Civil Engineering: ICASP9, 2003, San Francisco, CA, USA.

[24] Kircher CA, Whitman RV, Holmes WT. HAZUS Earthquake Loss Estimation Methods. Natural Hazards Review 2007;7(2): 45-59.

[25] Vamvatsikos D, Cornell CA. Incremental dynamic analysis. Earthquake Engineering \& Structural Dynamics 2001;31(3): 491-514.

[26] Ramirez CM, Miranda E. Building-Specific Loss Estimation Methods \& Tools for Simplified Performance-Based Earthquake Engineering. Technical Report No. 171, John A. Blume Earthquake Engineering Center, Stanford, CA, USA, 2009.

[27] Ramirez CM, Miranda E. Significance of residual drifts in building earthquake loss estimation. Earthquake Engineering \& Structural Dynamics 2012;41(11):1477-1493.

[28]CEN, EN 1998-3 Eurocode 8: Design of structures for earthquake resistance. Part 3, Assessment and retrofitting of buildings. European Committee for Standardization, Brussels, Belgium, 2005. 